\title{
Study of dielectric properties of 4-methylstyrene and $\alpha$-methylstyrene copolymer films with different molar ratio of initial monomers
}

\author{
(C) Ignat S. Dolgin, Pyotr P. Purygin, * and Yury P. Zarubin ${ }^{+}$ \\ Department of Inorganic Chemistry. Samara National Research University. \\ Moskovskoe Ave., 34. Samara, 443086. Samara Region. Russia. \\ Phone: +7 (846) 334-54-59. E-mail: puryginpp2002@mail.ru
}

\begin{abstract}
*Supervising author; ${ }^{+}$Corresponding author Keywords: copolymers, 4-methylstyrene, $\alpha$-methylstyrene, film, dielectric, dielectric properties, dielectric constant, dielectric loss tangent.
\end{abstract}

\begin{abstract}
Two new copolymers of 4-methylstyrene and $\alpha$-methylstyrene were obtained by the emulsion polymerization method according to the previously described and tested method in the course of the experiment in laboratory conditions. The molar ratio of the starting monomers of 4-methylstyrene and $\alpha$-methylstyrene was 9:2 and 10: 1, respectively, in each material sample. The structure of the copolymers obtained was confirmed by IR and ${ }^{1} \mathrm{H}$ NMR spectroscopy. Under laboratory conditions, three prototypes of each copolymer film were obtained from the solution. A sample of the copolymer was dissolved in methylene chloride was applied on a smooth glass substrate. After complete evaporation of the solvent, the film was separated from the substrate. The thickness of the films for each copolymer sample was 20,30 , and 50 microns. In the course of further experimentation, these samples were examined for the values of dielectric constant and tangent of dielectric loss angle. The basis of this experiment used a resonant method of measurement. The presented method is based on the variation of conductivity due to a change in the electrical capacitance of the oscillating circuit. In this experiment, the magnitude of the electrical capacitance and the tangent of the dielectric loss angle were measured. Based on the value of the capacitance and the parameters of the film sample to be measured, it is possible to calculate the dielectric constant. From the data obtained it can be seen that with increasing film thickness, dielectric constant values decrease. However, the indicators of the tangent of dielectric loss angle increase. With an increase in the measurement frequency, a slight decrease in the dielectric constant is observed, and the value of the tangent of the dielectric loss angle decreases nonlinearly. In addition, it should be noted that the samples of 4-methylstyrene- $\alpha$-methylstyrene copolymer films with a molar ratio of starting monomers of 10: 1 have a higher dielectric constant, along with lower values of the dielectric loss tangent. From this it follows that samples with a lower proportion of $\alpha$-methylstyrene in their structure have better dielectric characteristics compared with their counterparts with a high content of $\alpha$-methylstyrene.
\end{abstract}

\section{References}

[1] I.S. Dolgin, Yu.P. Zarubin, and P.P. Purygin. Investigation of the dielectric properties of styrene- $\alpha-$ methylstyrene copolymer obtained with various anionic and non-ionic emulsifiers. Butlerov Communications. 2017. Vol.52. No.11. P.144-146. DOI: 10.37952/ROI-jbc-01/17-52-11-144

[2] E.R. Blythe, D. Bloor. Electrical properties of polymers: trans. from English. Moscow: FIZMATLIT. 2008. 328p. (russian)

[3] V.K. Kryzhanovsky, V.V. Burlov, A.D. Panimatchenko, Yu.V. Kryzhanovskaya. Technical properties of polymeric materials. 2nd ed. St. Petersburg: Profession. 2005. 248p. (russian) 